\title{
Sporadic Abdominal Wall Desmoid type Fibromatosis: treatment paradigm after thirty two years
}

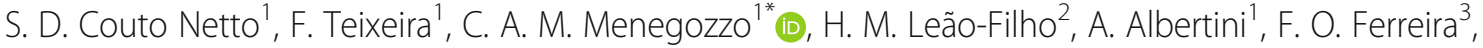 \\ E. H. Akaishi ${ }^{3}$ and E. M. Utiyama ${ }^{1}$
}

\begin{abstract}
Background: Desmoid-type fibromatosis is a benign mesenchymal neoplastic process. It exhibits an uncertain growth pattern and high recurrence rate. Previously radical surgical resection was the mainstay of treatment, but recently more surgeons are opting for conservative management with observation ("wait and see" policy). The authors intend to evaluate different therapeutic modalities and oncological outcomes for abdominal wall desmoid tumors.

Methods: We performed a retrospective study of patients who underwent surgical, hormonal or chemotherapy treatment for abdominal wall desmoid tumors between 1982 to 2014 at two institutions affiliated with the University of São Paulo, Brazil.

Results: In the study period, 32 patients were included. Twenty-seven patients had surgery upfront. Of those, 89\% were women with a median age of 33 years. Mean tumor size was $10 \mathrm{~cm}$. Pathology confirmed free margins in $92 \%$ of resections. Tumor recurrence rate was $11 \%$, with median relapse-free survival being 24 months. Multivariate analysis showed that positive final margins $(p<0.001)$ and positive frozen section $(p=0.001)$ were independent predictors of recurrence. For the 5 patients who underwent pharmacological therapy, median age was 33 years and median tumor diameter before treatment was $13 \mathrm{~cm}$. Four patients exhibited partial response by Response Evaluation Criteria in Solid Tumors (RECIST). The single patient who did not respond to RECIST underwent radiotherapy.

Conclusion: Desmoid tumor treatment has been evolving over the past decade towards a more conservative approach. Pharmacological treatment may result in tumor size regression. When surgical excision is indicated, positive margins represent an important prognostic factor for local tumor recurrence.
\end{abstract}

Keywords: Abdominal wall desmoid, Desmoid tumor, Non aggressive management, Watch and wait strategy

\section{Background}

Desmoid-type fibromatosis is a benign mesenchymal neoplasia with monoclonal proliferation [1]. Despite the increased recurrence rate after resection, it exhibits no metastatic potential [2]. Mac Farlane described the disease in 1832 [3]. However, the designation "desmoid"

* Correspondence: carlosmenegozzo@gmail.com

${ }^{1}$ Department of Surgery, Division of General Surgery and Trauma, Hospital das Clínicas - University of São Paulo, Av. Dr. Enéas de Carvalho Aguiar, 255, São Paulo 05403-010, Brazil

Full list of author information is available at the end of the article was given only in 1838 in reference to the Greek word "desmos" [4].

Desmoid-type fibromatosis is rare, comprising about $3 \%$ of soft-tissue tumors. Approximately $30 \%$ of patients have tumors related to Familial Adenomatous Polyposis (FAP), including those with a mutation on the APC gene [5]. Normally, sporadic desmoid tumors oncogenesis is associated with endocrine and physiologic factors such as estrogen hormonal stimulus and pregnancy [6-8]. Trauma and previous surgery may be related to he onset of the disease in up to $25 \%$ of the cases [2, 9-11].

Management has changed dramatically over the past decade. Radical surgery was the first line of treatment,

(c) The Author(s). 2018 Open Access This article is distributed under the terms of the Creative Commons Attribution 4.0 International License (http://creativecommons.org/licenses/by/4.0/), which permits unrestricted use, distribution, and reproduction in any medium, provided you give appropriate credit to the original author(s) and the source, provide a link to the Creative Commons license, and indicate if changes were made. The Creative Commons Public Domain Dedication waiver (http://creativecommons.org/publicdomain/zero/1.0/) applies to the data made available in this article, unless otherwise stated. 
with wide resection of the tumor and adjoining tissues. With surgical resection, local recurrence rates were between 10 and 40\%. In light of this, additional treatments (radiotherapy, chemotherapy, hormonal inhibitors and non-hormonal anti-inflammatories) have been used as adjuncts or even as first line therapy with more modern conservative approaches to treatement [12-18].

The aim of this study is to analyze management approaches and outcomes for patients with sporadic abdominal wall desmoid tumors treated at two large institutions affiliated with the University of São Paulo, Brazil.

\section{Methods}

Patients who underwent treatment for histologically confirmed abdominal wall desmoid tumor between 1982 and 2015 at Hospital das Clínicas (HC - FMUSP) and at Sao Paulo State Cancer Institute (ICESP) were retrospectively identified and analyzed. They were divided into two groups, those who were managed with surgery upfront, the surgical group (SG), and those who underwent a conservative non-surgical approach, the non-surgical group (NSG).

The information collected included the following variables: age, sex, previous pregnancy, previous scar at the desmoid location, tumor diameter, surgical margins (macroscopic incomplete, microscopic incomplete and microscopic complete resection), recurrence rate, postoperative morbidity and follow up. The status of resection margins follows the Union for International Cancer Control (UICC) R classification [19]. Since desmoid tumors exhibit an infiltrative scirrhous pattern, a microscopically positive margin may be present despite wide local resection. Given this, intraoperative frozen section is routintely performed and these results are included for analysis.

For nonoperative patients, tumor volume, method and duration of treatment, and median tumor volume reduction data were collected. In this group, response to therapy was assessed and classified according to Response Evaluation Criteria in Solid Tumors (RECIST) as complete or partial response, and stable or progressive disease.

All operations were performed by surgeons from the Sarcoma Group at each institution, and multimodal treatment was managed by clinical and radiation oncologists from ICESP.

\section{Statistical analysis}

Quantitative data were expressed using mean, median and percentage. Categorical variables were characterized by frequency distribution. Numerical variables were represented by central tendency measures (mean and median) and variability (variance and standard deviation).
Univariate analysis (Chi-Square for categorical and T-student test for continuous variables) was performed to assess statistical significance. Disease-free survival was obtained using the Kaplan-Meier method and multivariate analysis assessed independent prognostic factors for local recurrence. A $p$-value less than 0.05 was considered statistically significant.

\section{Results}

Thirty-two patients were treated for sporadic abdominal wall desmoid tumor in both institutions during the 32 -year period. Twenty-seven patients underwent operative management upfront (SG), 26 of them receiving treatment prior to 2012. The nonsurgical treatment group (NSG) comprised five patients, all managed after 2012. Patients underwent diagnostic core needle biopsy prior to receiving any therapy. Pathologic diagnosis was made by an instituational specialized sarcoma pathologist.

Table 1 summarizes the demographic data from the cohort. The majority of patients in both groups were not referrals, having their initial evaluation in our instituation.

During surgical resection, wide margins were targeted, with ideally two to three centimeters of disease free tissue in three dimensions. Limited resection was performed when the tumor was adjacent to critical structures (organs and major neurovascular bundles) so long as no signs of invasion were present. In $15 \%$ of the cases, ribs, bladder, and gallbladder were involved in the multivisceral resection specimen.

Frozen section detected $22 \%$ of compromised surgical margins, prompting extension of the initial resection. In the SG, final pathologic status revealed a mean tumor size of $10 \mathrm{~cm}$, ranging from 2 to $25 \mathrm{~cm}$, and $92.5 \%$ of microscopic free margins.

The estimated two and five-year recurrence-free survival (RFS) rates for the entire cohort were 92 and $87 \%$ respectively (Table 2, Fig. 1). Local recurrence (LR) was observed in 3 patients (11\%), including two in patients who had experience prior tumor recurrence. Mean time to recurrence was 24 months. Both patients with known compromised final margin status were already sent to our service with recurrent disease. The first patient underwent two interventions at our insituation, developed a second recurrence one year after the last procedure and doxorubicin treatment was initiated. Following this, she showed regression of the lesion size and is currently stable. The second patient exhibited recurrence 3 years after surgery. As per expert consensus following multidisciplinary tumor boards, systemic treatment was contraindicated due to the patient's comorbidities and she was then referred to radiotherapy due to disease progression.

Table 2 summarizes statistically significant findings based on multivariate analysis. Figure 2 displays the 
Table 1 Demographic characteristics of the 32 patients according to each group.

\begin{tabular}{|c|c|c|c|}
\hline & $S G(n=27)$ & \multicolumn{2}{|c|}{ NSG $(n=5)$} \\
\hline $\begin{array}{l}\text { Age at diagnosis (years) } \\
\text { Range }\end{array}$ & $\begin{array}{l}34 \text { years } \\
(19-88)\end{array}$ & \multicolumn{2}{|c|}{$\begin{array}{l}33 \text { years } \\
(22-56)\end{array}$} \\
\hline \multicolumn{4}{|l|}{ Gender } \\
\hline Female & $24(89 \%)$ & \multicolumn{2}{|c|}{$5(100 \%)$} \\
\hline Male & $3(11 \%)$ & \multicolumn{2}{|c|}{0} \\
\hline Previous surgery & $7(26 \%)$ & \multicolumn{2}{|c|}{$1(20 \%)$} \\
\hline Previous scar & $5(18 \%)$ & \multicolumn{2}{|c|}{$1(20 \%)$} \\
\hline Previous pregnancy & $19(70 \%)$ & \multicolumn{2}{|c|}{$3(60 \%)$} \\
\hline One & $7(37 \%)$ & \multicolumn{2}{|c|}{$2(66 \%)$} \\
\hline Two & $5(26 \%)$ & \multicolumn{2}{|c|}{$1(33 \%)$} \\
\hline Three or more & $7(37 \%)$ & \multicolumn{2}{|c|}{0} \\
\hline \multicolumn{4}{|l|}{ Disease } \\
\hline Primary & $25(92.5 \%)$ & \multicolumn{2}{|c|}{$5(100 \%)$} \\
\hline Recurrence & $2(7.5 \%)$ & \multicolumn{2}{|c|}{0} \\
\hline \multicolumn{4}{|l|}{ Surgical Margins } \\
\hline \multicolumn{4}{|l|}{ Frozen Section } \\
\hline RO & $21(78 \%)$ & \multicolumn{2}{|c|}{ N/A } \\
\hline R1 & $6(22 \%)$ & \multicolumn{2}{|c|}{ N/A } \\
\hline \multicolumn{4}{|l|}{ Final margin status } \\
\hline RO & $25(92.5 \%)$ & \multicolumn{2}{|c|}{ N/A } \\
\hline R1 & $2(7.5 \%)$ & \multicolumn{2}{|c|}{ N/A } \\
\hline Tumor size $(\mathrm{cm})$ & & $\begin{array}{l}\text { Pre } \\
\text { treatment }\end{array}$ & $\begin{array}{c}\text { Post } \\
\text { treatment }\end{array}$ \\
\hline Median & 10 & 13.2 & 7,6 \\
\hline Range & $2-25$ & $9.7-29.9$ & $2.8-23.7$ \\
\hline Recurrence & $3(11 \%)$ & & \\
\hline Mean follow-up (months) & 82 & & \\
\hline
\end{tabular}

recurrence-free survival rates according to margin status. The importance of intraoperative frozen section and its results in the management of this disease is highlighted. Age and tumor diameter did not predict an increased risk of LR.

SG patients underwent abdominal wall reconstruction after tumor resection. Twenty patients had onlay polypropylene mesh placement after midline fascial closure. In the 5 patients where midline fascial closure was not feasible, a cellulose-base mesh appropriate for bowel contact was placed. Two patients had primary fascial closure with no mesh. Eight patients in SG developed some form of postoperative complication. Five had wound infection and one had deep vein thrombosis. No significant long-term morbidity was noted in these patients. There was one case of evisceration in a patient without mesh and a single case of bowel erosion in a paitent who received cellulose-based mesh.
All NSG patients in the group were from after 2012, and treatment began as a combination of nonsteroidal anti-inflammatories (NSAIDs) plus anti-estrogens (celecoxib $200 \mathrm{mg}$ plus tamoxifen $40 \mathrm{mg}$ ) or intravenous chemotherapy (doxorubicin $75 \mathrm{mg} / \mathrm{m}^{2}$ for six cycles). The choice between regimens was based on symptoms such as pain, disease progression, and the need for a faster response rate.

Three patients were initially treated with doxorubicin $75 \mathrm{mg} / \mathrm{m}^{2}$ for six cycles, followed by tamoxifen $20 \mathrm{mg}$ and celecoxib $200 \mathrm{mg}$ per day was used until ideal tumor response was achieved. NSAID plus antiestrogen therapy was first line in the two other patients. Mean length of conservative treatment was 28 months (ranging from 9 to 42 months). In four patients (80\%) there was a partial response, and one showed disease progression while on tamoxifen and celecoxib. This single patient was referred for radiotherapy. No patient had complete response, and mean tumor size after treatment was $7.6 \mathrm{~cm}(2.8-23.7 \mathrm{~cm})$.

\section{Discussion}

Desmoid-type fibromatosis is a clonal fibroblastic proliferative lesion which typically infiltrates surrounding structures and tends to recur, but exhibits no metastatic potential [1]. These tumors are divided into three broad groups: abdominal, extra and intraperitoneal. The latter is especially prevalent in FAP patients. Disease incidence has increased in the last few decades. While earlier reports from Reitamo et al. [20] mentioned 2 to 4 new cases per million inhabitants, a recent national database reported an incidence of 5.36 patients per million people [21].

Desmoid tumors occurs mainly in fertile young women due to hormonal influences, especially during pregnancy, or in patients with previous exposure to trauma [20, 22, 23]. As expected, in our patients group $90 \%$ were women, $62.5 \%$ had previous pregnancies, three had tumor growth during pregnancy, and 19\% presented with tumors at the site of previous scars.

Based on clinical suspicion, all patients underwent core needle biopsy to establish diagnosis before initiation of any treatment. National databases have reported that desmoid tumor resection after diagnositic biopsy enhances the margin status by differentiating from other locally aggressive mesenchymal tumors [21]. Complete macroscopic resection has been the first choice of treatment for both primary tumors and recurrent disease. However, surgery alone is associated with high risk of LR ranging from less than $10 \%$ [24-28] to $40 \%$ at abdominal locations, and up to $70 \%$ in extra-abdominal disease [29]. Wide resection margins are performed with the goal of complete microscopic resection and subsequently imporved long-term outcomes, especially local recurrence. 
Table 2 Results of multivariable analysis of predictive factors for recurrence

\begin{tabular}{|c|c|c|c|c|}
\hline & \multirow{2}{*}{$\begin{array}{l}\text { Number of } \\
\text { patients }\end{array}$} & \multicolumn{2}{|c|}{ Recurrence-free Survival (\%) } & \multirow[t]{2}{*}{$p$-value } \\
\hline & & 2-year & 5-year & \\
\hline Overall recurrence-free survival & 27 & 92.6 & 87.7 & - \\
\hline \multicolumn{5}{|l|}{ Age (years) } \\
\hline$<34$ & 14 & 92.6 & 92.6 & \multirow[t]{2}{*}{0.514} \\
\hline$>34$ & 13 & 100 & 82.6 & \\
\hline \multicolumn{5}{|l|}{ Diameter $(\mathrm{cm})$} \\
\hline$<8$ & 15 & 100 & 93.3 & \multirow[t]{2}{*}{0.678} \\
\hline$>8$ & 12 & 91.7 & 91.7 & \\
\hline \multicolumn{5}{|l|}{ Frozen section margin $(n=26)$} \\
\hline Free & 20 & 83.3 & 46.3 & \multirow[t]{3}{*}{0.001} \\
\hline Compromised & 6 & 100 & 100 & \\
\hline Not done & 1 & - & - & \\
\hline \multicolumn{5}{|l|}{ Final margin status } \\
\hline Free & 25 & 0 & - & \multirow[t]{2}{*}{$<0.001$} \\
\hline Compromised & 2 & 100 & 95.3 & \\
\hline \multicolumn{5}{|c|}{ Margins upon both frozen section and final status $(n=26)$} \\
\hline Compromised/Compromised & 2 & 0 & - & \multirow[t]{3}{*}{$<0.001$} \\
\hline Compromised/Free & 4 & 71.4 & 71.4 & \\
\hline Free/Free & 20 & 100 & 100 & \\
\hline
\end{tabular}

The impact of microscopic margins on recurrence is the most controversial prognostic factor associated with desmoid tumors. Many studies from high-volume centers reveal different opinions concerning resection extension and prognosis. There is no consensus that negative microscopic margins improve local relapse [14, 30-35], however other series report the role of negative margins in predicting low or no local recurrence at all $[12,36-40]$. Two desmoid tumor series from the same institution, at different times, observed conflicting results when analyzing free margins in intraoperative frozen section as independent factors associated with recurrence.

Tumor size is also another controversial prognostic factor for recurrence; several studies correlate size with local relapse. He et al. [41] analyzed 114 sporadic desmoids and observed that tumors larger than $8 \mathrm{~cm}$ were more likely to recur (HR: $2.43-95 \% \mathrm{CI}: 1.15-5.13$ $p=0.021)$. Bertani et al. [16] found that desmoid diameter greater than $10 \mathrm{~cm}$ predicted recurrence on univariate analysis but failed to demonstrate this with multivariate analysis (HR: $2.6895 \%$ CI - $0.43-16.67$

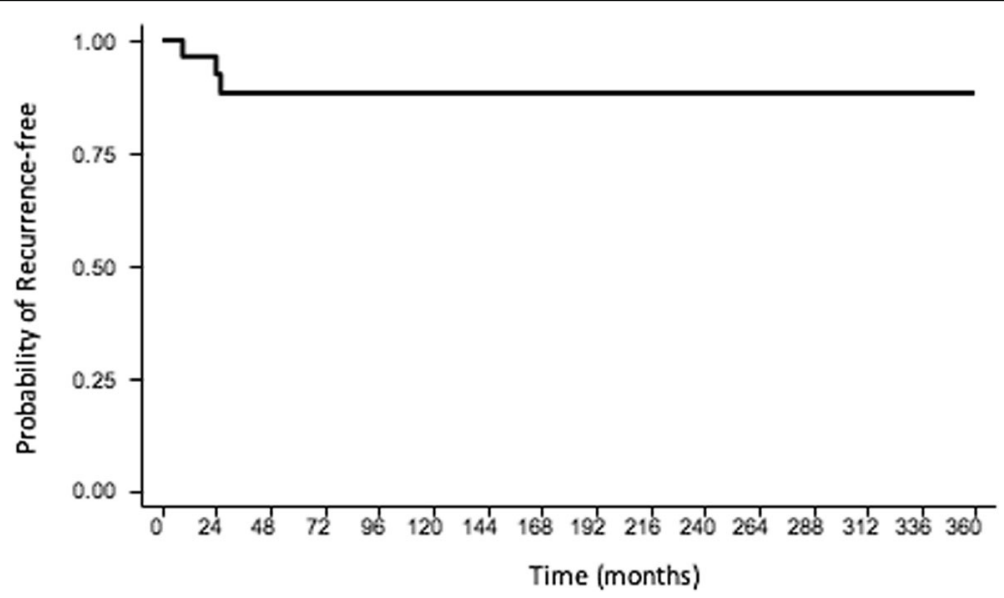

Fig. 1 Recurrence-free overall survival of the patients who underwent surgery upfront $(S G, n=27)$ 


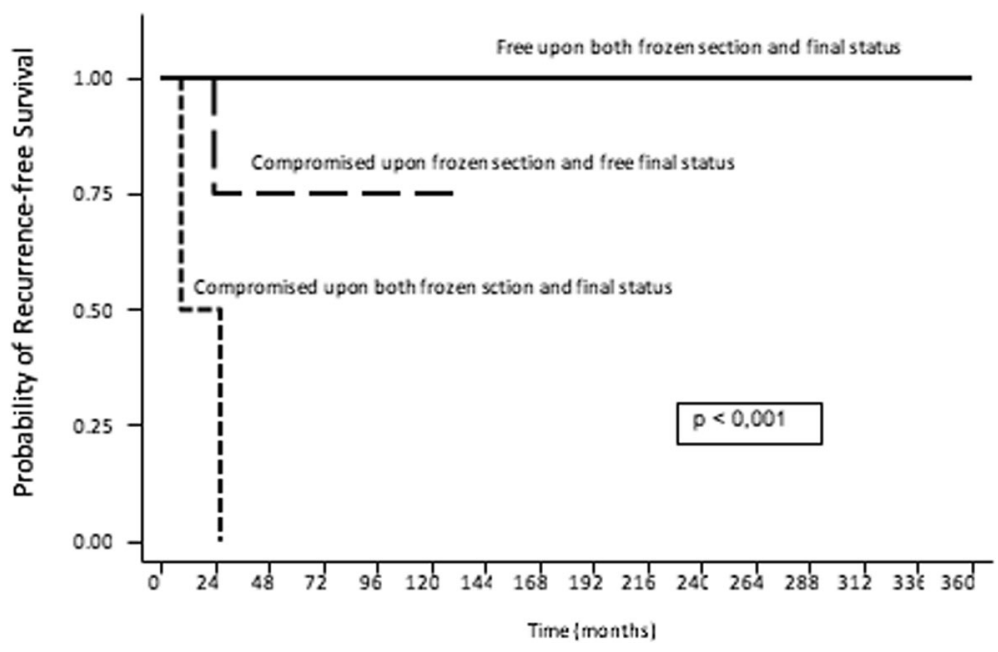

Fig. 2 Recurrence-free survival rates according to margin status for patients who underwent surgery upfront (SG, $n=27$ )

$p=0.29)$. In the largest desmoid series, Crago et al. [42], analyzed 495 patients and found that size over $10 \mathrm{~cm}$ was a significant independent factor for local relapse on both uni and multivariate analysis (HR: 1.94-95\% CI 1.23-3.05 $p=0.004$ ). However, in our study, tumors larger than $7.5 \mathrm{~cm}$ were not associated with local recurrence $(p=0.51)$. Correlation between size and local recurrence was not found in other studies [15, 30, 31, 38].

Age has been reported as a major factor for local relapse. In some series, lower age predicts recurrence and relapse. Crago et al. discovered more relapse in patients younger than 26 years old (HR: 4.27, $p=0.006$ ) [42]. Similar findings were made by other authors such as Spear et al., who demonstrated a lower threshold of 18 years as high-risk for recurrence [32]. Sorensen et al. and $\mathrm{He}$ et al. observed that patients younger than 32 and 30 years-old were almost five times more likely to recur (HR: $4.97 p=0.009$ ) [33, 41]. In our series, age was not an independent factor for local recurrence, in keeping with similar results from other experienced sarcoma institutions [14, 26, 30, 34, 38, 43, 44].

Tumor location is an important prognostic factor for sporadic fibromatosis. Abdominal tumors show better prognosis than extra-abdominal desmoid tumors $[15,42$, 45 ], and surgery alone achieves superior disease control compared to other locations in these patients [46]. Patients undergoing resection for an abdominal wall desmoid tumor have a long-term disease-free survival rate of more than $90 \%$, whereas in young patients with large tumors located in an extremity this rate is less than $40 \%$ [29, 31, 47-52]. Large wide resections appear to be safe. Nevertheless, more extensive surgery is associated with more severe complications, early and late morbidity such as hernias, mesh complications, and the need for reoperation. Over the past ten years, there has been an ongoing trend towards intitial conservative management in large desmoid tumors or asymptomatic patients [14].

Major problems in managing desmoid tumors are their locoregional aggressiveness and their high recurrence after initial surgery, present in up to $40 \%$ of the cases [53]. Given that desmoid tumor is a benign disease and that no patient will die from it, radical surgery may be overly aggressive. In light of the considerable risk of recurrence and the potential morbidity, a conservative approach has been advocated for in the past 5 to 10 years.

Pharmacological treatment and simple observation arose as conservative approaches. Observation is the first option in some sarcoma centers, especially after the promising results published by Bonvalot et al. in 2008 [14]. However, changes in the treatment course might occur due to symptoms of pain or disease progression. In this scenario, hormonal or even chemotherapy is the next choice of treatment. Patients with large lesions $(>7 \mathrm{~cm})$ have pharmacological treatment as their first line of therapy [26]. A simple treatment algorithm already in use in some centers [54] is presented in Fig. 3.

All patients in the NSG presented with significant lesions (mean size of $13 \mathrm{~cm}$ ), pain, and palpable masses at diagnosis. Therefore, they were all treated with chemo or hormonal therapy. Eighty percent had a partial response according to RECIST, with a mean tumor volume reduction of $31 \%$ (20 to $78 \%$ ). The patient who had a major partial response by RECIST was operated on with radical intent that yielded clear microscopic margins. There was no evidence of disease after a short follow-up. In this scenario, radical surgery is not well established in the literature. There is, however, a trend offer surgery to poor responders as long as clear margins are obtainable [26].

This study is limited by its retrospective nature and its potential for selection bias, as the population submitted 


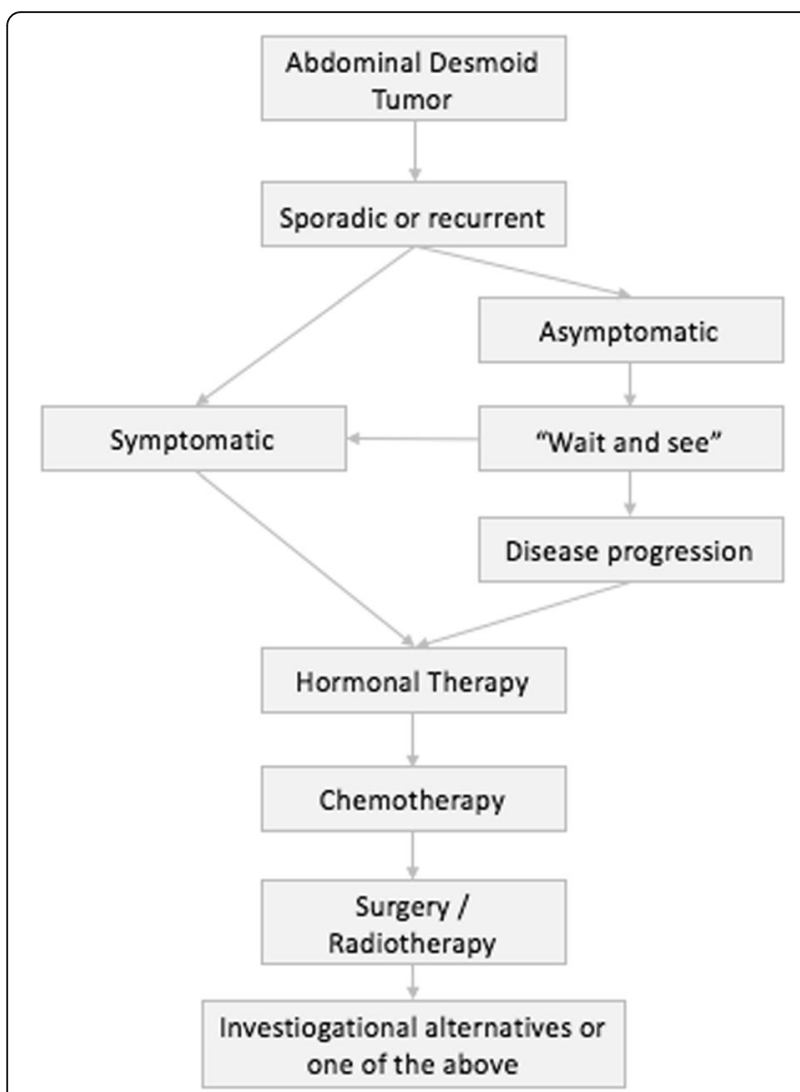

Fig. 3 Treatment Algorithm (modified from Gronchi et al. Sporadic desmoid-type fibromatosis: A stepwise approach to a non-metastasising neoplasm - A position paper from the Italian and the French Sarcoma Group. Annals of Oncology 2014;25 [3]:578-83)

to surgery may be different from those allocated to the nonoperative group. However, our results show that complete microscopic removal is an independent prognostic factor for LR. Our series also reflects the historical heterogeneity of management strategies that most sarcoma centers have experienced over time.

\section{Conclusion}

Over the past decades, there has been a change in the management of desmoid tumors towards a more conservative approach. A "wait and see" policy has been initially adopted in most cases. Medical treatment plays an important role in reducing the size of the tumors. Adoption of such treatment may avoid extensive resections and associated morbidity. When surgical resection is indicated, free margins should be pursued in order to lower the risk of local recurrence.

\section{Abbreviations}

FAP: Familial Adenomatous Polyposis; HC-FMUSP: Hospital das Clínicas; ICESP: São Paulo State Cancer Institute; LR: Local recurrence; NSAID: nonsteroidal anti-inflammatory drugs; NSG: Non-surgery Group; RECIST: Response Evaluation Criteria In Solid Tumors; RFS: Recurrence-free survival; SG: Surgery Group; UICC: Union for International Cancer Control

\section{Acknowledgments}

We thank Dr. Brandon Van Asseldonk for the invaluable help in reviewing the manuscript writing and making the necessary corrections.

\section{Availability of data and materials}

data and material are available to any researcher interested upon reasonable request to the corresponding author.

\section{Authors' contributions}

SDCN: data collection, literature review, article writing; FTJr: data collection, article writing; CAMM: article writing, manuscript review; $A A$ : data collection; EHA: manuscript review and final modifications; EMU: manuscript review and final modifications. All authors read and approved the final manuscript.

\section{Ethics approval and consent to participate}

The study has been approved by the institution's Ethics Committee (Comissão de Ética para Análise de Projetos de Pesquisa - CAPPesq) under the number $115 / 16$. Consent to participate was waivered do to the retrospective nature of the study (CAPPesq, 115/16).

\section{Consent for publication}

The study does not involve personal identifiable data.

\section{Competing interests}

The authors declare that they have no competing interests.

\section{Publisher's Note}

Springer Nature remains neutral with regard to jurisdictional claims in published maps and institutional affiliations.

\section{Author details}

${ }^{1}$ Department of Surgery, Division of General Surgery and Trauma, Hospital das Clínicas - University of São Paulo, Av. Dr. Enéas de Carvalho Aguiar, 255, São Paulo 05403-010, Brazil. ²Departament of Radiology and Diagnostic Imaging, São Paulo Cancer Institute (ICESP), University of São Paulo, São Paulo, Brazil. '3ão Paulo Cancer Institute (ICESP), University of São Paulo, São Paulo, Brazil.

Received: 19 December 2017 Accepted: 24 May 2018 Published online: 07 June 2018

\section{References}

1. Fletcher CDM, Bridge JA, Hogendoorn P, Mertens F. WHO classification of tumours of soft tissue. WHO Classif Tumours Soft Tissue Bone Fourth Ed. 2013;46:10-2.

2. Singer S, Maki R, O'Sullivan B. Soft tissue sarcoma. In: DeVita Jr VT, Lawrence TS, Rosenberg SA, editors. Cancer: principles and practice of oncology. 9th ed. Philadelphi, PA: Lippincott Williams \& Wilkins; 2011. p. 1533-77.

3. MacFarlane J. Clinical reports of the Surg Pract of the Glasgow Royal Infirmary. Glasgow: D. Robertson; 1832. p. 63-6.

4. Müller J. Erste Lieferung. Über den feineren Bau und die Formen der krankhaften Geschwülste. Berlin: G. Reimer; 1838. p. 60.

5. Singer S, Nielsen T, Antonescu C. Molecular biology of soft tissue sarcoma. In: DeVita V. T. Jr., Lawrence T. S. RSA, editor. Cancer: principles and practice of oncology. 9th ed. Philadelphia: Lippincott Williams \& Wilkins; 2011. p. 1522-1532.

6. Durkin A, Korkolis D, Al-Saif O, Zervos E. Full-term gestation and transvaginal delivery after wide resection of an abdominal desmoid tumor during pregnancy. J Surg Oncol. 2005;89(2):86-90.

7. Priolli DG, Martinez CAR, Mazzini DLS, de CAF S, Piovesan H, Nonose R. Tumor desmóide da parede abdominal durante a gravidez: relato de caso. Rev Bras Ginecol e Obs. 2005;27(5):283-8.

8. Awwad J, Hammoud N, Farra C, Fares F, Abi Saad G, Ghazeeri G. Abdominal Wall Desmoid during pregnancy: diagnostic challenges. Case Rep Obstet Gynecol. 2013;2013:350894.

9. Tejpar S, Nollet F, Li C, Wunder JS, Michils G, dal Cin P, et al. Predominance of beta-catenin mutations and beta-catenin dysregulation in sporadic aggressive fibromatosis (desmoid tumor). Oncogene. 1999;18(47):6615-20.

10. Lazar AJF, Tuvin D, Hajibashi S, Habeeb S, Bolshakov S, Mayordomo-Aranda $E$, et al. Specific mutations in the $\beta$-catenin gene (CTNNB1) correlate with 
local recurrence in sporadic desmoid tumors. Am J Pathol. 2008;173(5): 1518-27.

11. von Mehren M, Randall RL, Benjamin RS, Boles S, Bui MM, Conrad EU, et al. Soft tissue sarcoma, version 2.2016, NCCN clinical practice guidelines in oncology. J Natl Compr Cancer Netw. 2016;14(6):758-86.

12. Lev D, Kotilingam D, Wei C, Ballo MT, Zagars GK, Pisters PWT, et al. Optimizing treatment of desmoid tumors. J Clin Oncol. 2007;25(13):1785-91.

13. Mullen JT, Delaney TF, Kobayashi WK, Szymonifka J, Yeap BY, Chen Y, et al. Desmoid tumor: analysis of prognostic factors and outcomes in a surgical series. Ann Surg Oncol. 2012;19(13):4028-35.

14. Bonvalot S, Eldweny H, Haddad V, Rimareix F, Missenard G, Oberlin O, et al. Extra-abdominal primary fibromatosis: aggressive management could be avoided in a subgroup of patients. Eur J Surg Oncol. 2008;34(4):462-8.

15. Peng PD, Hyder O, Mavros MN, Turley R, Groeschl R, Firoozmand A, et al. Management and recurrence patterns of desmoids tumors: a multiinstitutional analysis of 211 patients. Ann Surg Oncol. 2012;19(13):4036-42.

16. Bertani E, Testori A, Chiappa A, Misitano P, Biffi R, Viale G, et al. Recurrence and prognostic factors in patients with aggressive fibromatosis. The role of radical surgery and its limitations. World J Surg Oncol. 2012;10(184):1-7.

17. Mankin HJ, Hornicek FJ, Springfield DS. Extra-abdominal desmoid tumors: a report of 234 cases. J Surg Oncol. 2010;102(5):380-4.

18. Berri RN, Baumann DP, Madewell JE, Lazar A, Pollock RE. Desmoid tumor: current multidisciplinary approaches. Ann Plast Surg. 2011;67:551-64.

19. Brierley JD, Gospodarowicz MK, Wittekind C, editors. TNM classification of malignant tumors. 8th ed. West Sussex: Wiley-Blackwell; 2017.

20. Reitamo JJ, Hayry P, Nykyri E, Saxen E. The desmoid tumor. I. Incidence, sex-, age- and anatomical distribution in the Finnish population. Am J Clin Pathol. 1982;77(6):665-73.

21. van Broekhoven DLM, Grünhagen DJ, den Bakker MA, van Dalen T, Verhoef C. Time trends in the incidence and treatment of extra-abdominal and abdominal aggressive Fibromatosis: a population-based study. Ann Surg Oncol. 2015;22(9):2817-23.

22. Hayry P, Reitamo JJ, Totterman S, Hopfner-Hallikainen D, Sivula A. The desmoid tumor. II. Analysis of factors possibly contributing to the etiology and growth behavior. Am J Clin Pathol. 1982;77(6):674-80.

23. Häyry P, Reitamo JJ, Vihko R, Jänne $O$, Scheinin TM, Tötterman S, et al. The desmoid tumor. III. A biochemical and genetic analysis. Am J Clin Pathol. 1982;77(6):681-5.

24. Wilkinson MJ, Chan KE, Hayes AJ, Strauss DC. Surgical outcomes following resection for sporadic abdominal wall fibromatosis. Ann Surg Oncol. 2014; 21(7):2144-9.

25. Bertani E, Chiappa A, Testori A, Mazzarol G, Biffi R, Martella S, et al. Desmoid tumors of the anterior abdominal wall: results from a monocentric surgical experience and review of the literature. Ann Surg Oncol. 2009;16(6):1642-9.

26. Bonvalot S, Ternes N, Fiore M, Bitsakou G, Colombo C, Honore C, et al. Spontaneous regression of primary abdominal wall desmoid tumors: more common than previously thought. Ann Surg Oncol. 2013;20(13):4096-102.

27. Latchford AR, Sturt NJH, Neale K, Rogers PA, Phillips RKS. A 10-year review of surgery for desmoid disease associated with familial adenomatous polyposis. Br J Surg. 2006;93(10):1258-64.

28. Catania G, Ruggeri L, luppa G, Di Stefano C, Cardì F, luppa A. Abdominal wall reconstruction with intraperitoneal prosthesis in desmoid tumors surgery. Updat Surg. 2012;64(1):43-8.

29. Markhede G, Lundgren L, Bjurstam N, Berlin Ö, Stener B. Extra-abdominal desmoid tumors. Acta Orthop. 1986;57(1):1-7.

30. Mullen JT, Delaney TF, Kobayashi WK, Szymonifka J, Yeap BY, Chen Y, et al. Desmoid Tumor: Analysis of Prognostic Factors and Outcomes in a Surgical Series. Ann Surg Oncol. 2012;40:28-35.

31. Posner MC, Shiu MH, Newsome JL, Hajdu SI, Gaynor JJ, Brennan MF. The desmoid tumor. Not a benign disease Arch Surg. 1989;124(2):191-6.

32. Spear MA, Jennings LC, Mankin HJ, Spiro IJ, Springfield DS, Gebhardt MC, et al. Individualizing management of aggressive fibromatoses. Int J Radiat Oncol Biol Phys. 1998;40(3):637-45.

33. Sørensen A, Keller J, Nielsen OS, Jensen OM. Treatment of aggressive fibromatosis: a retrospective study of 72 patients followed for 1-27 years. Acta Orthop Scand. 2002;73(2):213-9.

34. Ballo MT, Zagars GK, Pollack A, Pisters PWT, Pollock RA. Desmoid tumor: prognostic factors and outcome after surgery, radiation therapy, or combined surgery and radiation therapy. J Clin Oncol. 1999;17(1):158-67.
35. Huang K, Fu H, Shi Y-Q, Zhou Y, Du C-Y. Prognostic factors for extraabdominal and abdominal wall desmoids: a 20-year experience at a single institution. J Surg Oncol. 2009;100(7):563-9.

36. Guadagnolo BA, Zagars GK, Ballo MT. Long-term outcomes for Desmoid tumors treated with radiation therapy. Int J Radiat Oncol Biol Phys. 2008; 71(2):441-7.

37. Salas S, Dufresne A, Bui B, Blay JY, Terrier P, Ranchere-Vince D, et al. Prognostic factors influencing progression-free survival determined from a series of sporadic desmoid tumors: a wait-and-see policy according to tumor presentation. J Clin Oncol. 2011;29(26):3553-8.

38. Merchant NB, Lewis JJ, Woodruff JM, Leung DHY, Brennan MF. Extremity and trunk desmoid tumors: a multifactorial analysis of outcome. Cancer. 1999;86(10):2045-52.

39. Gronchi A, Casali PG, Mariani L, Lo Vullo S, Colecchia M, Lozza L, et al. Quality of surgery and outcome in extra-abdominal aggressive Fibromatosis: a series of patients surgically treated at a single institution. J Clin Oncol. 2003;21(7):1390-7.

40. Baumert BG, Spahr MO, Von Hochstetter A, Beauvois S, Landmann C, Fridrich $\mathrm{K}$, et al. The impact of radiotherapy in the treatment of desmoid tumours. An international survey of 110 patients. A study of the rare Cancer network. Radiat Oncol. 2007;2(1):12.

41. He XD, Zhang YB, Wang L, Tian ML, Liu W, Qu Q, et al. Prognostic factors for the recurrence of sporadic desmoid- type fibromatosis after macroscopically complete resection : Analysis of 114 patients at a single institution. Eur J Surg Oncol. 2015;41:1013-9.

42. Crago AM, Denton B, Salas S, Dufresne A, Mezhir JJ, Hameed M, et al. A prognostic nomogram for prediction of recurrence in desmoid fibromatosis. Ann Surg. 2013;258(2):347-53.

43. Fu CY, Wu SC, Chen RJ, Wang YC, Chung PK, Yeh CC, et al. Evaluation of pelvic fracture stability and the need for angioembolization: pelvic instabilities on plain film have an increased probability of requiring angioembolization. Am J Emerg Med. 2009;27(7):792-6.

44. Ozger H, Eralp L, Toker B, Ağaoğlu F, Dizdar Y. Evaluation of prognostic factors affecting recurrences and disease-free survival in extra-abdominal desmoid tumors. Acta Orthop Traumatol Turc. 2007:41(4):291-4.

45. Phillips SR, A'Hern R, Thomas JM. Aggressive fibromatosis of the abdominal wall, limbs and limb girdles. Br J Surg. 2004;91(12):1624-9.

46. Francis WP, Zippel D, MacK LA, Difrancesco LM, Kurien E, Schachar NS, et al. Desmoids: a revelation in biology and treatment. Ann Surg Oncol. 2009; 16(6):1650-4.

47. Plukker JT, van Oort I, Vermey A, Molenaar I, Hoekstra HJ, Panders AK, et al. Aggressive fibromatosis (non-familial desmoid tumour): therapeutic problems and the role of adjuvant radiotherapy. Br J Surg. 1995:82(4):510-4.

48. Easter DW, Halasz NA. Recent trends in the management of desmoid tumors. Summary of 19 cases and review of the literature. Ann Surg. 1989; 210(6):765-9.

49. Higaki S, Tateishi A, Ohno T, Abe S, Ogawa K, lijima T, et al. Surgical treatment of extra-abdominal desmoid tumours (aggressive fibromatoses). Int Orthop. 1995;19(6):383-9.

50. Lopez R, Kemalyan N, Moseley HS, Dennis D, Vetto RM. Problems in diagnosis and management of desmoid tumors. Am J Surg. 1990;159(0002-9610 (Print)): 450-3.

51. Boris S, Markhede G, Lundgren L, Blurstam N. Extra-abdominal desmoid tumors. Acta Orthop Scand. 1986;57(1):1-7.

52. Mendenhall WM, Zlotecki RA, Morris CG, Hochwald SN, Scarborough MT. Aggressive fibromatosis. American journal of clinical oncology: Cancer Clinical Trials. 2005;28:211-5.

53. Gronchi A, Raut CP. Optimal approach to sporadic desmoid tumors: from radical surgery to observation. Time for a consensus? Ann Surg Oncol. 2012; 19(13):3995-7.

54. Gronchi A, Colombo C, Le Péchoux C, Dei Tos AP, Le Cesne A, Marrari A, et al. Sporadic desmoid-type fibromatosis: a stepwise approach to a nonmetastasising neoplasm-a position paper from the Italian and the French sarcoma group. Ann Oncol. 2014;25(3):578-83. 